\title{
Coloured light pollution in the urban environment
}

\author{
J. Kowalska*1 \\ ${ }^{1}$ Faculty of Electrical Engineering, Warsaw University of Technology, Koszykowa 75, 00-662 Warszawa
}

Received August 16, 2019; accepted October 02, 2019; published December 31, 2019

\begin{abstract}
The article deals with issues related to colored lighting occurring in urban space. Exemplified by the Colosseum Amphitheatre 3D model, applications of colorful illumination were shown and the rationale for using color in individual cases was discussed. The aim of the article is to draw attention to proper planning and modernization of lighting to limit the negative interference of light in the ecosystem.
\end{abstract}

The use of light at night has significant advantages, which improve people's life. Among the most important benefits like greater safety for pedestrians and drivers, it also reduces fear of crime and increases the number of social activities which can be done outside after dark [1]. Despite the above-mentioned benefits, lighting could have also a bad impact on the wellbeing of humans and animals. In the publications [2-4] the impact of the blue light hazard on human alertness, depression, chronic fatigue syndrome and sleeplessness was discussed. It is widely known that the blue part of the light spectrum powerfully suppresses melatonin and triggers people's working activity. Frequent exposure to blue light during the night influences the circadian rhythm and human health.

A number of studies on the influence of high colour light saturation were conducted on a group of animals (turtle, insects) [5-6]. The experiment with turtles showed that white light and blue light interrupt their natural ability to walk to the water after hatching and lead to their population dwindling. The experiment on insects showed that diverse species of insects react differently to various colours of light. All the research showed that the use of colour light strongly influences the environment. It is important to use colour in outdoor lighting with caution.

Road lighting, floodlighting and outdoor lighting contribute to the phenomenon of light pollution. Nowadays, it is not possible to avoid this phenomenon but it is possible to limit its intensity. Outdoor lighting research showed how to reduce light pollution by using appropriate luminaries and indicated the most environmentally friendly spectral power distribution of light sources [7-10]. The reduction of light emission in the upper half-space and avoidance of high colour temperature diodes can be applied in road and park lighting. However, it is difficult to meet these

*E-mail: justyna.kowalska@ien.pw.edu.pl requirements in the case of a floodlighting project in which the main criterion is the appearance of the building, aesthetic emotions and artistic vision of the designer.

The choice of light distribution and proper fixture placement has a significant impact on the emission of light into the atmosphere. Properly designed illumination should direct the light to where it is needed and prevent light emission beyond the building's outline. Figure 1 shows examples of the wrong direction of a light beam and the proper design of a light pattern is shown in Fig. 2.
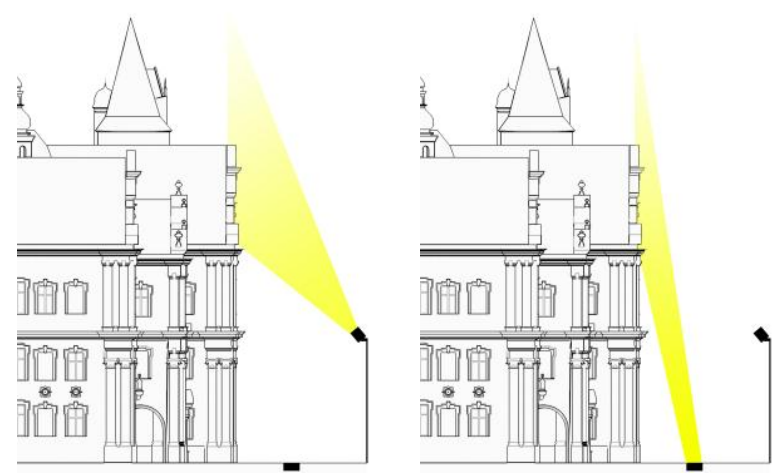

Fig. 1. Examples of wrong light direction.

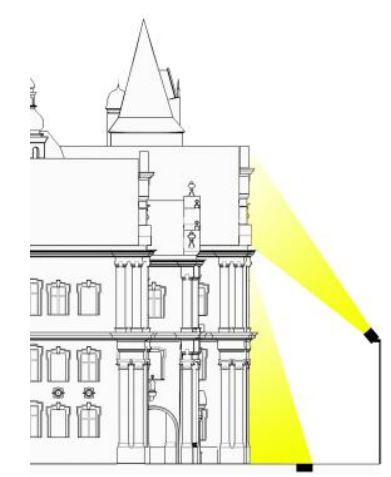

Fig. 2. Example of proper light direction.

The popularity of a floodlighting project and widespread use of white light illumination introduced a routine in the image of cities. Investors started to look for alternatives which could promote and distinguish their buildings from the rest of the city. After the market introduction of LED 
fixtures with a control system, their needs were fulfilled. Since then, there has been a growing popularity of colourful illumination. Moreover, the lack of standards or recommendations regarding colourful floodlighting gives full freedom in its applications. It creates visual and lighting chaos which has a significant impact on the environment [11-12].

The use of colour, especially in the multi-coloured version, looks well on a simple modern architectural shape of the building (Fig. 3). Therefore, it is reasonable to apply it to modern buildings and make them more attractive during the nighttime. With a more complicated architectural detail which has a historical value, the colour combination draws attention to itself and the architecture becomes invisible (Fig. 4).

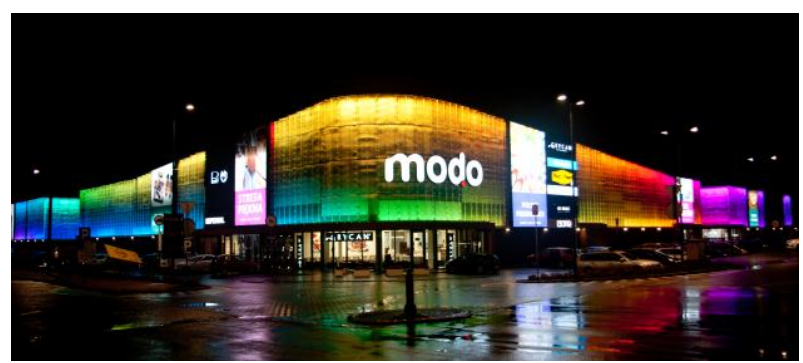

Fig. 3. Colourful floodlighting of modern building.

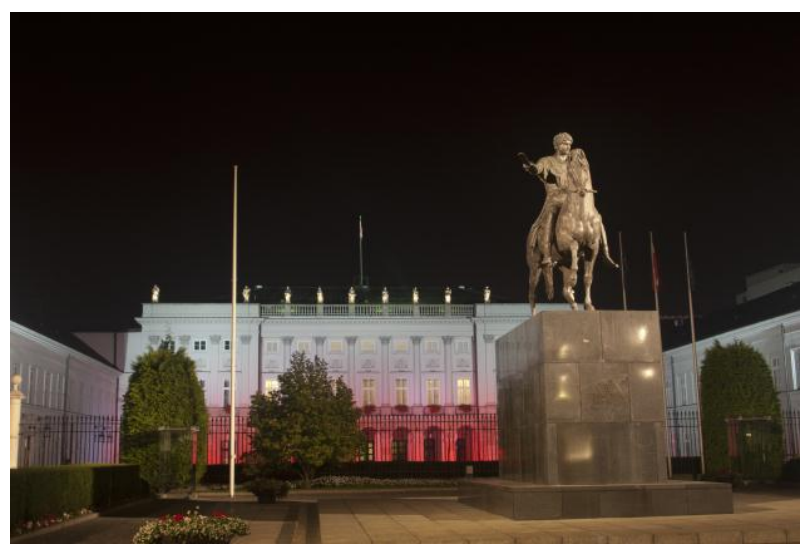

Fig. 4. Colourful floodlighting of the Presidential Palace in Warsaw.

The application of colour to the floodlighting project was made on the example of Colosseum 3D model. The shape of the building is a good example to show what is the difference between colourful lighting application and the use of colour accent in the project. For better understanding of questionable usage of only colour light, four different lighting scenes were designed and shown as examples (Fig. 5). Vivid colours don't correspond to the historical value of this place or association with human and animal suffering. The old structured walls which contain holes are not well-visible. These projects do not emphasize the characteristic features of the building and hide all the history behind the colours.

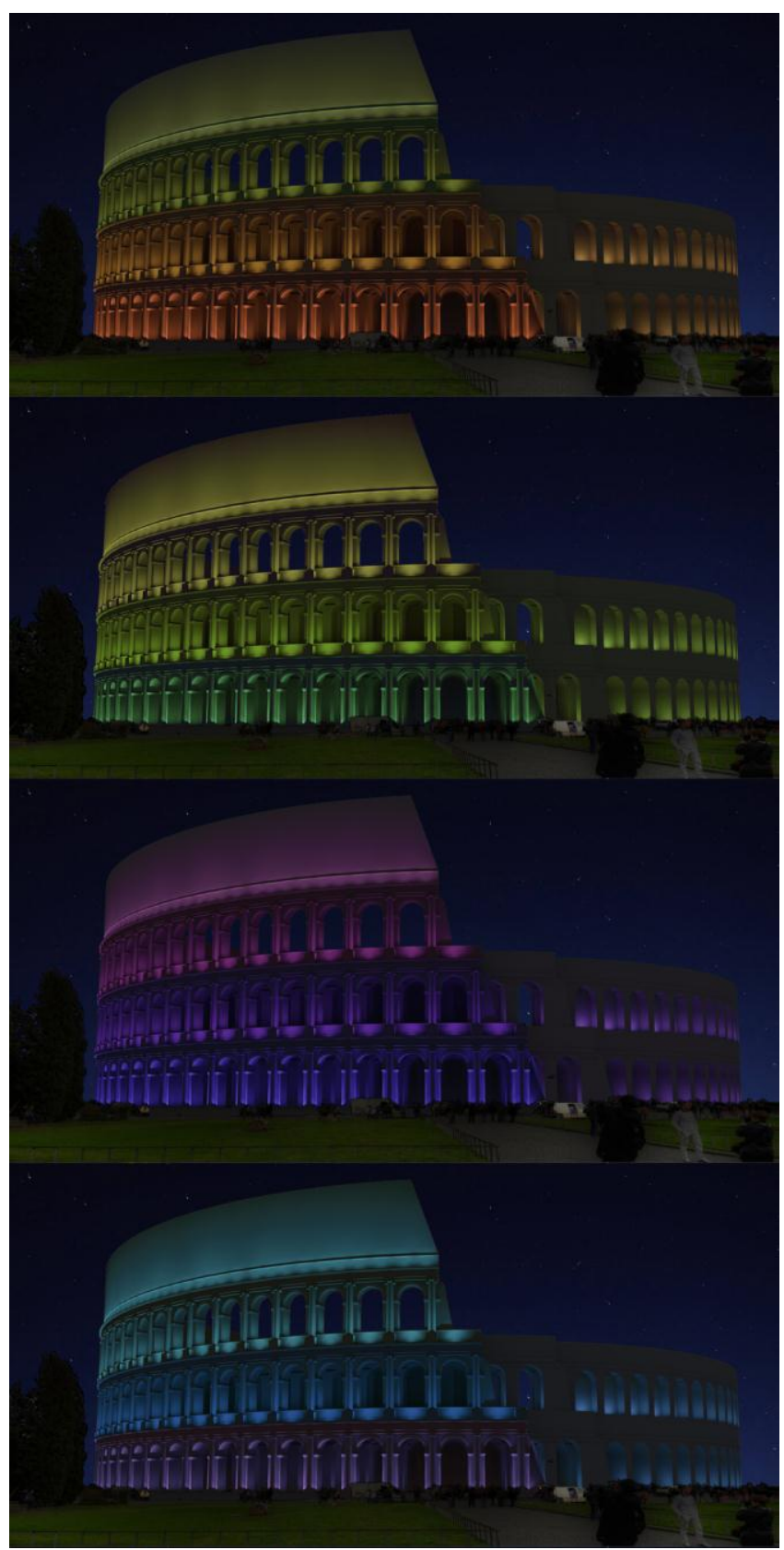

Fig. 5. Four variants of colour illumination of the Colosseum.

The introduction of colour in places with a history should be designed reasonably. To reduce the impact of colour light on the environment, the project should be based on the white light and colour accents. The colours which are chosen should be emotionally compatible with the role of the place. The first two lighting projects shown in Fig. 6 use a warm white light to emphasize the building's age. The direction of light allows to bring out 
the play between the light and shadow while the accents of colour highlight the innocence or brutality of the place.

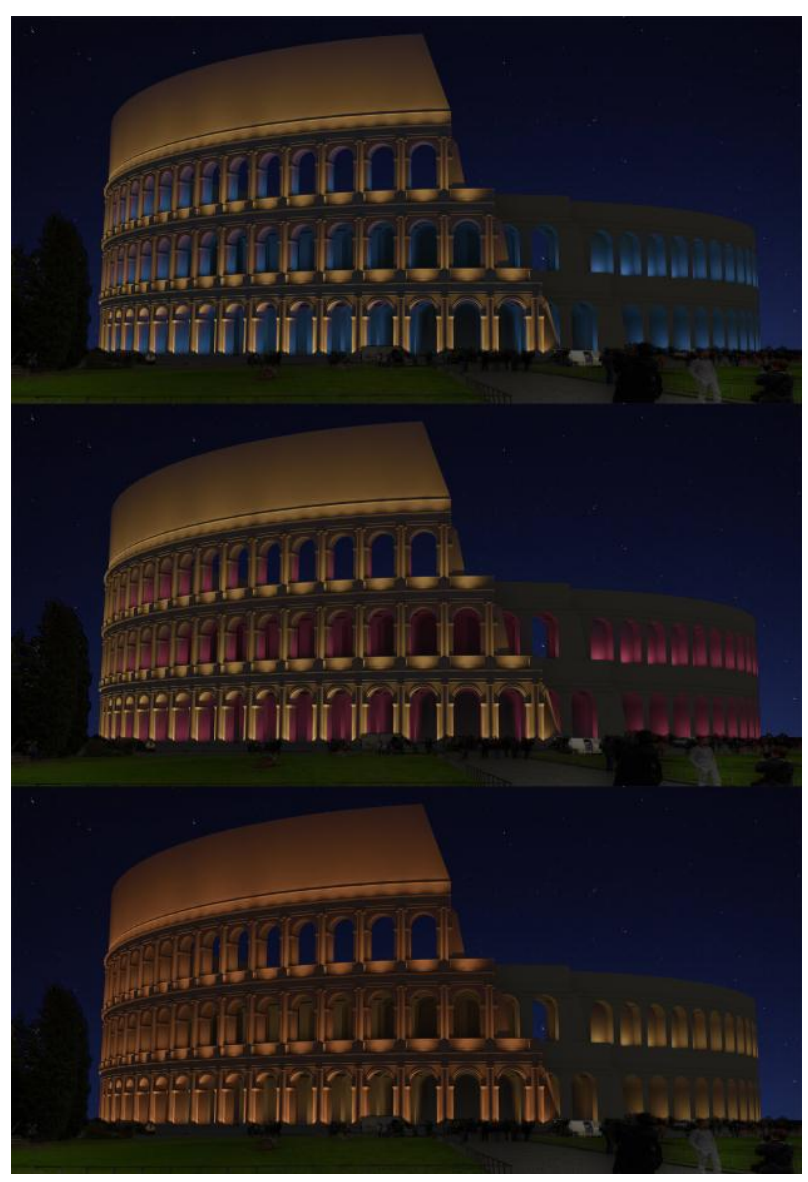

Fig. 6. Examples of using colour accents in floodlighting.

The design is consistent with the theme of the place and does not overwhelm the viewers with the number of colours used.

The third visualization shown in Fig. 6, represents a different approach to the issue. A warm yellow (almost orange) light is used as dominant, whereas the arcades are lit by a bright yellow light. This project highlights the age and heaviness of the building.

All three projects are well-planned and maintain the atmosphere of the place. However, a good project of one building could also generate the city's "colour pollution". To avoid the visual chaos of individual places which are designed in different styles, it is justified to adopt an urban masterplan, define the light pattern and set the most important places. The design of the masterplan could also reduce the amount of light and generate financial and environmental benefits.

The use of colour light in outdoor applications is not necessary but it is eye-catching. To restore some order in the use of a colour light at night, the rules to follow must be defined. In order to succeed, the lighting of the building should be designed with a white light in mind. Only then should the designers ask themselves a question if the colour is needed. Adjusting the colour to the minimum and, if possible, reducing the saturation to provide less destructive colour light to the environment, are also good options. Taking care of the lighting details could generate benefits for our wellbeing and decrease the number of civilization diseases. However, the light shouldn't be demonized. Without it we will not have the opportunity to see anything during the night except the stars.

\section{References}

[1] P.R. Boyce, Building and Environment 151, 356 (2019).

[2] Y. Hu, T. Zhang, J. Chen, D. Ma, C. Cheng, Israel J. Chem. 54, 979 (2014).

[3] W. Jernarczyk, Kosmos 64, 625 (2015).

[4] J.D. Bullough, M.S. Mies, J. Illuminating Eng. Society 29, 6 (2013).

[5] M. Rivas., P.T. Santidrian, J.U. Dieguez, A. Marco, J. Experimental Marine Biology and Ecology 463, 143 (2015).

[6] S. Marcinkowska, E. Tęgowska, Kosmos 64, 589 (2015).

[7] P. Jakubowski, Kosmos 64, 643 (2015).

[8] K. Skarżyński, Kosmos 64, 553 (2015).

[9] P. Tabaka, I. Fryc, Kosmos 64, 669 (2015).

[10] W. Żagan, K.Skarżyński, Light and Engineering 25, 75 (2017).

[11] J. Kowalska, Polish J. for Sustainable Development 21, 69 (2017).

[12] C. Gardner, Optics \& Laser Technology 38, 366 (2006). 